\title{
Injector Fouling and Its Impact on Engine Emissions and Spray Characteristics in Gasoline Direct Injection Engines
}

\author{
Sebastian Henkel, Yannis Hardalupas, and Alexander Taylor \\ Imperial College London \\ Christopher Conifer, Roger Cracknell, and Tor Kit Goh \\ Shell Global Solutions \\ Paul-Benjamin Reinicke, Marc Sens, and Michael Rieß \\ IAV GmbH, Germany
}

\begin{abstract}
In Gasoline Direct Injection engines, direct exposure of the injector to the flame can cause combustion products to accumulate on the nozzle, which can result in increased particulate emissions. This research observes the impact of injector fouling on particulate emissions and the associated injector spray pattern and shows how both can be reversed by utilising fuel detergency. For this purpose multi-hole injectors were deliberately fouled in a four-cylinder test engine with two different base fuels. During a four hour injector fouling cycle particulate numbers $(\mathrm{PN})$ increased by up to two orders of magnitude. The drift could be reversed by switching to a fuel blend that contained a detergent additive. In addition, it was possible to completely avoid any PN increase, when the detergent containing fuel was used from the beginning of the test. Microscopy showed that increased injector fouling coincided with increased particulate emissions. Based on these results a selection of the injectors was installed in a laboratory injection chamber and the spray patterns were investigated with a high speed camera. Injectors corresponding to the largest PN drift produced the thinnest spray jets with the deepest penetration. These factors amplify the risk of wall wetting and provide an explanation for the increase of PN. The positive effect of the detergent was also reflected in the spray pattern analysis, which illustrates the potential benefits of such fuel additives.
\end{abstract}

CITATION: Henkel, S., Hardalupas, Y., Taylor, A., Conifer, C. et al., "Injector Fouling and Its Impact on Engine Emissions and Spray Characteristics in Gasoline Direct Injection Engines," SAE Int. J. Fuels Lubr. 10(2):2017, doi:10.4271/2017-01-0808.

\section{INTRODUCTION}

Unlike in port fuel injection (PFI) systems, gasoline direct injection (GDI) engines deliver fuel directly into the combustion chamber. This opens up the possibility of new injection strategies and can improve efficiency and fuel consumption, especially under partial load $[\underline{1}, \underline{2}$, 3]. An additional advantage is the so-called stratified charge operation, which allows adjustment of the injection and ignition timings of the engine, to further optimise engine operation [4]. In addition, the charge cooling effect observed during fuel injection allows for the use of higher compression ratios, with reduced risk of knocking. These benefits are gaining more attention with the continuing trend of downsizing and super- or turbocharging of engines, due to increasingly strict emissions regulations $[\underline{5}, \underline{6}, \underline{7}]$. Additional benefits of GDI are the option to completely shut-off fuel supply while coasting [] $]$ and improved cold start behaviour compared to PFI engines $[\underline{9}, \underline{10}]$.

One major challenge of the GDI concept, however, is the potential for increased formation of particulate emissions. Recent emissions legislations such as EURO 6 in Europe and LEV III (Low Emissions
Vehicle Program) in the US pose very strict limitations on particle number and mass (PM) concentrations $[\underline{11}, \underline{12}]$. Methods to control particulate emissions from GDI engines are therefore important.

Introduction of an injector into the combustion chamber of a GDI engine results in direct exposure of the injector tip to the harsh conditions occurring during combustion. Because the flame directly interacts with the nozzle, combustion products can be deposited on the surface and inside cavities. This is usually referred to as injector fouling or coking and can have an adverse effect on fuel consumption, engine performance and both hydrocarbons and particulate emissions. Formation of deposits on the injector tip can result in alteration of spray pattern leading to increased spray impingement and therefore increased particulate emissions $[\underline{13}, \underline{14}, \underline{15}, \underline{16}]$.

The phenomenon of injector fouling and how it is influenced by fuel and engine parameters was the focus of a number of studies. Aradi et al. [17] investigated different fuel blends under several conditions in a four cylinder engine. They used rich fuel-to-air ratios in order to promote fouling. By measuring the temperature of the injector tip with an internal sensor, they saw that with increasing temperature 
inside the engine the level of fouling also increased and the injector performance, measured by the flow loss, decreased. By changing the composition of the fuel blend and increasing its overall volatility, fouling was also promoted, as was increasing the olefin content. In later work of Aradi et al. $[\underline{18}, \underline{19}]$ they showed that the formation of injector deposits can be controlled by the use of fuel additives. Depending on the detergent type, they were able to reverse or avoid any injector flow loss caused by fouling. Analogous effects of fuel additives were also reported by other groups $[\underline{13}, \underline{14}, \underline{20}, \underline{21}]$. These publications all show a decrease of injector performance caused by fouling and illustrate potential benefits of fuel additives. The mechanism behind the build-up and removal of deposits with detergents is complex and not in the scope of this investigation. Detailed information on this topic can however be found in the literature. $[\underline{18}, \underline{19}, \underline{22}, \underline{23}, \underline{24}]$

One pressing issue associated with injector fouling is the increase of engine out emissions, which is a concern for direct injection systems. Arters et al. [23] performed vehicle and laboratory tests. During their experiments they saw a clear correlation between the level of injector fouling and the increase of particulate emissions. In the worst case particle mass was three-fold compared to the clean system. They also reported a negative effect on hydrocarbons, carbon monoxide and $\mathrm{NO}_{\mathrm{x}}$. By switching the engines to a detergent containing fuel they were able to reverse these changes. Research performed by Carlislei et al. [25] further demonstrated the link between injector fouling and increase in engine-out emissions. Both hydrocarbon and soot levels increased with the build-up of deposits. Under homogeneous operating conditions, increased T90 of the fuel and increased engine load promoted the fouling process under their conditions. When switching to stratified injection, a levelling out of the engine emissions was observed, most likely due to stabilisation of the fouling. Overall, the use of detergents was beneficial in most cases.

A possible reason for the increase in particulate numbers (PN) due to injector fouling, aside from the change in injector performance and fuel impingement, was given by Berndorfer et al. [26]. Their tests in a single-cylinder engine, equipped with an endoscope, showed the formation of a rich diffusion flame stabilizing on the injector tip during the combustion phase. The residue build-up on the surface acted like a sponge absorbing fuel during injection, which upon combustion resulted in a rich flame. The integral intensity of the flame was used as a measure of its extent and was directly correlated to the particulate numbers measured at the exhaust. Once they removed the deposits from the surface mechanically, they no longer observed these issues. Additionally, by increasing the injection pressure they were able to reduce the size of the flame and eventually completely avoid it. With this research, Berndorfer et al. provide additional explanation for the increase of particulate emissions, aside from the increased probability of wall wetting and pool fires. This phenomenon was also studied by Wang et al. [27]].

The research presented in this paper is a collaborative effort. In the first phase of the study, engine tests were run with and without detergent additives to observe the effect on injector tip deposit formation and particulate emissions. Different fuel blends (see Table 1) were used in an engine dirty-up cycle to deliberately foul injectors. Under engine operation some of these injectors were subsequently exposed to a fuel blend with a detergent additive. For all cases engine performance and emissions were monitored. In the second phase of the experiment both fouled and cleaned-up injectors were taken from the engine tests and analysed visually with a microscope before conducting spray pattern analysis. The intention was to correlate potential changes in the spray pattern to the extent of the fouling and emissions drift.

\section{EXPERIMENTAL SETUP AND PROCEDURES}

\section{Engine Setup, Fuel Blends and Test Cycles}

All engine tests were performed in a four cylinder VW EA211 GDI engine. The injectors (VW part number 04E $906036 \mathrm{E}$ ) have a multi-hole design with five nozzles located around the centre of the tip. A photograph of one unused injector can be seen in Figure 1, with a close-up view of the injector tip and the numbering of each nozzle. Each of the holes has a different orientation relative to the injector normal, with an axis symmetric design between hole 1, 2 and 4,5 . These pairs create sprays that are pointed outwards at an angle. Hole 3 is orientated almost parallel to the injector normal. The injector is mounted inside the engine with hole \#3 pointed towards the spark plug at the top and the 4 other holes targeted downwards. All nozzles have a diameter of about $200 \mu \mathrm{m}$ and a static flow rate of $6.44 \mathrm{mg} / \mathrm{ms}$ at a rail pressure of $100 \mathrm{bar}, 7.98$ $\mathrm{mg} / \mathrm{ms}$ at 150 bar and $9.23 \mathrm{mg} / \mathrm{ms}$ at $200 \mathrm{bar}$, based on the measurements of one injector.

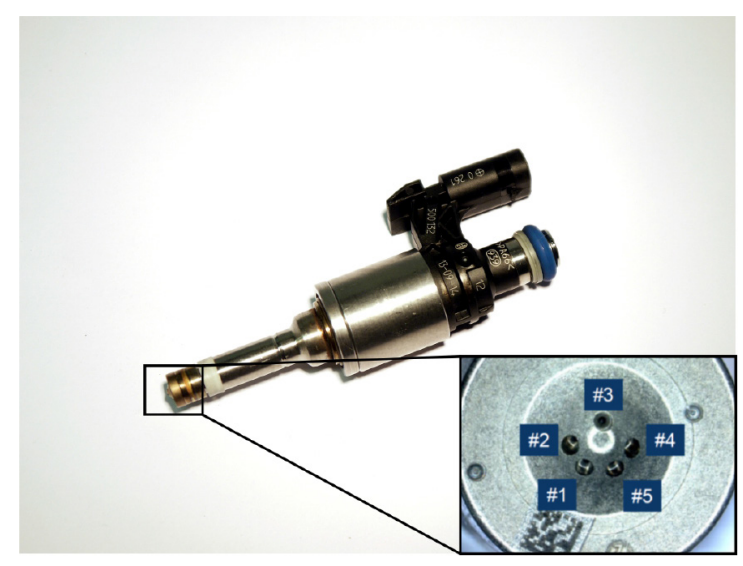

Figure 1. Multi-hole injector used in the EA211 engines with a close-up view of the injector tip and numbering of each nozzle.

Table 1. Overview of the fuel blends used during the engine cycles.

\begin{tabular}{|c|c|c|c|}
\hline Fuel Blend & $\begin{array}{c}\text { Detergent } \\
\text { Content }\end{array}$ & $\begin{array}{c}\text { Aromatic } \\
\text { Content, vol\% }\end{array}$ & T90, ${ }^{\circ} \mathrm{C}$ \\
\hline A & 0 & 40 & 134.3 \\
\hline B & Low & 40 & 134.3 \\
\hline C & High & 40 & 134.3 \\
\hline D & 0 & 20 & 173.9 \\
\hline
\end{tabular}




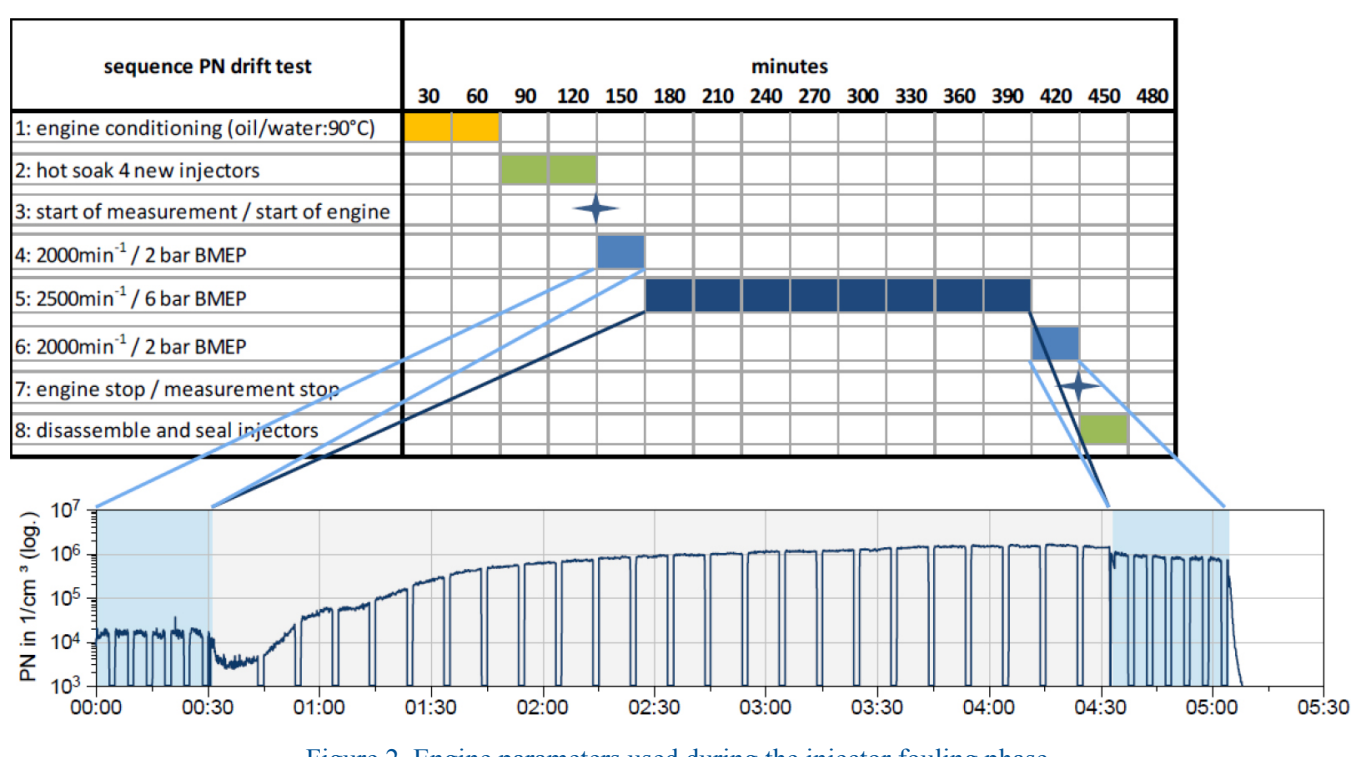

Figure 2. Engine parameters used during the injector fouling phase.

In total 32 injectors, in sets of four, were used in the engines with four different fuel blends. All injectors were selected at random from the manufacturing line but originated from same batch. An overview of the different blends is shown in Table 1. Two base fuels (Fuel A and Fuel D) were used with high and low aromatic content as well as different distillation behaviour (T90). By adding a detergent to Fuel A at a low and high concentration Fuel B and Fuel C were created, respectively.

The engine experiment was divided into two different stages, an injector fouling phase and an injector clean-up phase. During the former injectors were exposed to Fuels A, B, C and D. Each run produced a set of four injectors for each fuel blend. This yielded in a total number of 16 fouled injectors. The engine parameters and an overview of the injector fouling phase are shown in Figure 2.

After conditioning the engine and hot soaking of the injectors for 60 minutes in total, the fouling cycle and measurements were started. During the first 30 minutes the engine was operated at $2000 \mathrm{rpm}$ at 2 bar BMEP and a rail pressure of 100 bar in order to create a reference point for engine performance and emission levels. After this, the engine speed was increased to $2500 \mathrm{rpm}$ at 6 bar BMEP and $200 \mathrm{bar}$ rail pressure. This phase lasted four hours. Finally, the operating conditions were changed back to $2000 \mathrm{rpm}, 2$ bar BMEP and 100 bar for 30 minutes. The start of ignition (SOI) was set to $260^{\circ} \mathrm{CA}$ for the lower and $285^{\circ} \mathrm{CA}$ for the higher operating point. After finalising the engine experiments the respective injectors were removed from the engines and sealed for later analysis.

The injector fouling cycle was repeated for a second run with sets of fresh injectors following the same procedure. Upon completion, however, the injectors remained in the engine and were used in the injector clean-up cycle. This was done by switching to Fuel C, which contained the detergent at high concentration. The operating procedure of the clean-up cycle followed that of the fouling cycle, with the exception that the experiment was run for eight hours instead of four. During both cycles, engine emissions in the form of particle number and particle mass were analysed with an AVL 489 particulate counter. The dilution ratios were adjusted to accommodate for an expected increase of 2000-3500 in particle numbers during the fouling stage. Additionally, hydrocarbon, $\mathrm{CO}$ and $\mathrm{NO}_{\mathrm{x}}$ emissions were recorded. The fuel trim was also monitored.

Upon completion of the engine experiments all injectors were sealed and the extent of their deposits were analysed by microscopy and compared to the emissions drift. After this, all injectors were installed in the laboratory injection chamber to record the spray patterns.

\section{Injection Chamber and Recording Setup}

The 32 injectors, 16 from the injector fouling cycle and 16 from the clean-up cycle were installed in a laboratory injection chamber in order to record and correlate the spray pattern changes to the fouling level and emissions drift observed during the engine experiments. An overview of the setup is shown in Figure 3.

The setup comprised of a cube-like injection chamber with a length of $300 \mathrm{~mm}$, sealed by Perspex windows on the sides. The frame was mounted on a steel base plate with ports connected to the laboratory extraction system in order to remove fumes created by evaporating fuel. The rear of the chamber was closed with an aluminium plate, which formed the support for the transparent impingement plate, with its overall dimensions of $150 \times 170 \mathrm{~mm}^{2}$ and ports to connect a heat exchanger (Julabo ME-12, Julabo UK LTD), which was used to temperature control the surface. Top and bottom of the frame were sealed with quartz glass windows (UQG Optics). The thickness of the entire assembly was $20 \mathrm{~mm}$. The liquid used in the heat exchangers was silicone oil (Rhodorsil 47V100, Bentley Advanced Materials).

The top of the injection chamber was closed with another aluminium panel, which formed the structural support of the injector mount. The orientation of the injector in this assembly was perpendicular to the impingement plate at a distance of $45 \mathrm{~mm}$. The fuel delivery was achieved with a pneumatically actuated pump (MSF22, Maximator $\mathrm{GmbH}$ ). In order to minimise pressure fluctuations caused by the injector needle, a $155 \mathrm{ml}$ pressure cylinder (Swagelok Ltd.) was connected to the pressure side of the pump. During measurements, the rail pressure was set to 160 bar and a $1.25 \mathrm{~ms}$ injection width was 
selected. This equates to an approximated fuel mass of $10.29 \mathrm{mg}$ per injection, based on the static fuel mass presented in the previous chapter. The surface temperature was set to $20^{\circ} \mathrm{C}$. The injectors were powered and operated with a dedicated control unit (GN068-00-230, Control Unit for HDEV 5.2 with PN2130 Driver Stage and Control Unit CJ840, Gantec $\mathrm{GmbH}$ ) and the electronic triggering profile of the EA211 engine control unit was replicated.

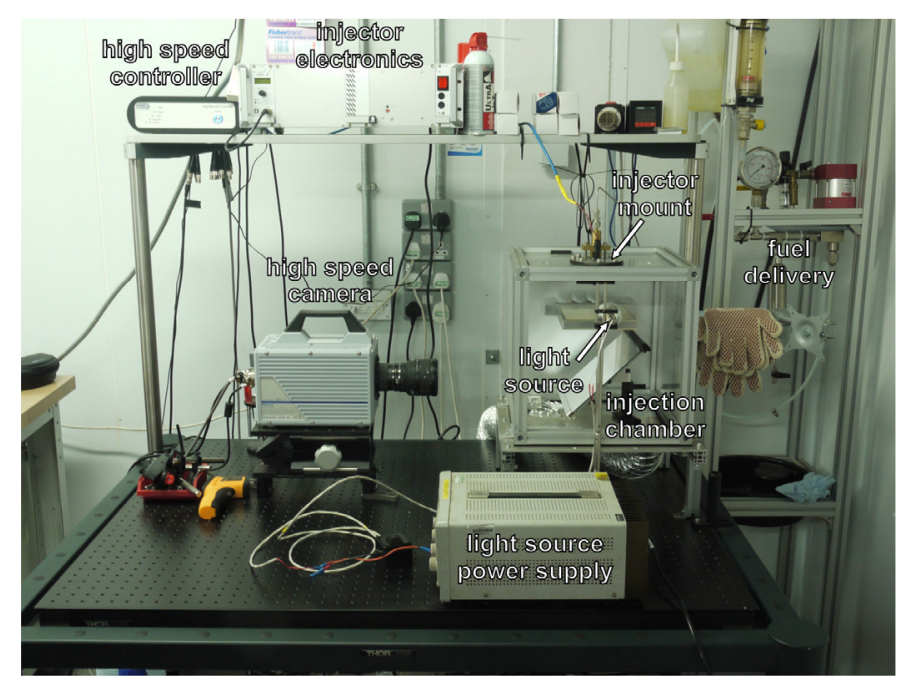

Figure 3. Experimental setup used to investigate the spray patterns.

The recordings were done with a 12 bit high speed CMOS camera (HighSpeedStar 6, LaVision $\mathrm{GmbH}$ ) at 20000 frames per second and $25 \mu$ s exposure. The resolution was reduced to $512 \times 512$ pixels in order to achieve the desired frame rate. The lens was a Nikon $50 \mathrm{~mm} \mathrm{f} / 1.4$. The camera was mounted horizontally on a lab jack and the viewing direction was redirected with a $45^{\circ}$ mirror inside the injection chamber. This way a bottom up view of the spray pattern was recorded.

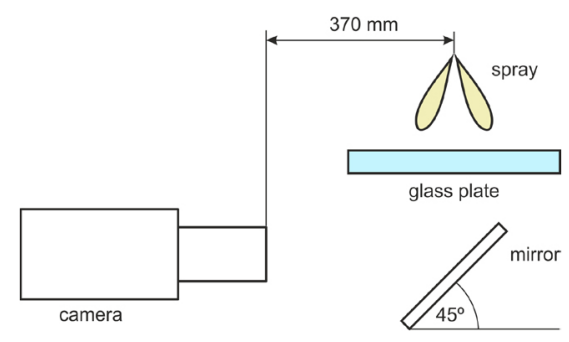

a.

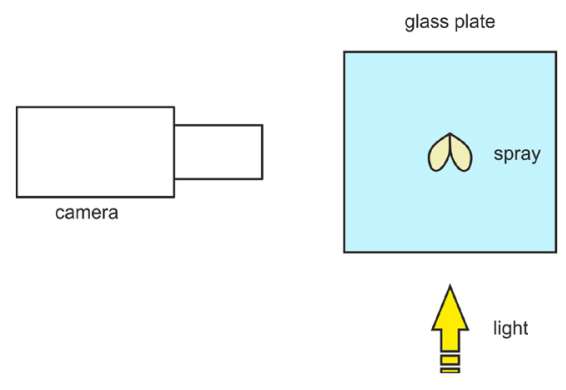

b.

Figure 4. Elevation view (a) and plan view (b) of the optical alignment used to record the fuel spray patterns.
The spray was illuminated with a $50 \mathrm{~W}$ halogen light source, powered by a $12 \mathrm{~V}$ AC to DC power supply (IPS1810H, ISO-TECH). The light source had an illumination angle of $48^{\circ}$ and was positioned outside the injection chamber at a $90^{\circ}$ angle from the camera axis, in the centre between the injector tip and plate. Figure 4 shows an illustration of the optical alignment.

All raw images were captured in Davis 7.2 (LaVision GmbH) and processed in Matlab 2013b. A total of 50 injections were recorded and averaged for each injector. This was done to minimise fluctuations caused by injection to injection variances. Additionally, in order to test for mechanical cleaning caused by injection without combustion, spray patterns of different injectors were tested for changes over the course of 500 injections. None of the new, fouled and cleaned-up injectors tested showed any changes and it is fair to assume that potential erosion of the deposits during measurements can be neglected. In addition to the 32 injectors from the two cycles, two new and unused injectors were used to align the setup and create reference points.

\section{ENGINE RESULTS}

The engine tests were split into an injector fouling cycle and an injector clean-up cycle. The latter was using Fuel $\mathrm{C}$ only. The main focus of these experiments was to observe an increase in particulate emissions caused by injector fouling, which were quantified as particle number and particle mass concentrations. The results obtained during the injector fouling cycle can be seen in Figure 5. $\mathrm{CO}, \mathrm{NO}_{\mathrm{x}}$ and fuel trim did not show any change during both cycles. Only the hydrocarbon levels increased slightly during the fouling cycle and dropped back to their original levels throughout the cleanup cycle.

As described above, during the first 30 min of measurement, the engine was run at a lower speed and load, with a reduced rail pressure. In that phase, particulate emission levels of all fuels remain relative constant with values between $1 \cdot 10^{4}$ and $3 \cdot 10^{4}$ particles per $\mathrm{cm}^{3}$. After the conditions were changed to the higher operating point of the engine, particulate numbers begin to deviate from their original levels. In case of Fuel A and D a rapid growth can be seen at around 60-70 minutes. Within 30 minutes values increase more than 50 fold. From this point onwards, the increase levels off and maximum values larger than $1 \cdot 10^{6} 1 / \mathrm{cm}^{3}$ are reached. The overall highest particle concentrations are produced by Fuel A with numbers larger than $2.4 \cdot 10^{6} 1 / \mathrm{cm}^{3}$. In contrast to Fuels A and D, the two detergent containing blends (Fuel B and Fuel C) do not give a notable change in PN throughout the operating condition with higher speed and load. Values stabilise in this phase at about a quarter of the numbers detected during the starting phase and remain steady at around $2.5 \cdot 10^{3} 1 / \mathrm{cm}^{3}$, which corresponds to the PN concentration that can be found in ambient laboratory air. In the shutdown phase of the experiment (final $30 \mathrm{~min}$ ), the emission values tapered off slightly in the case of blends A and D, but were still almost two orders of magnitude larger than the values recoded at the beginning of the injector fouling cycle. In case of Fuel B and C particle numbers went back up to the values measured at the beginning. 
Henkel et al / SAE Int. J. Fuels Lubr. / Volume 10, Issue 2 (June 2017)
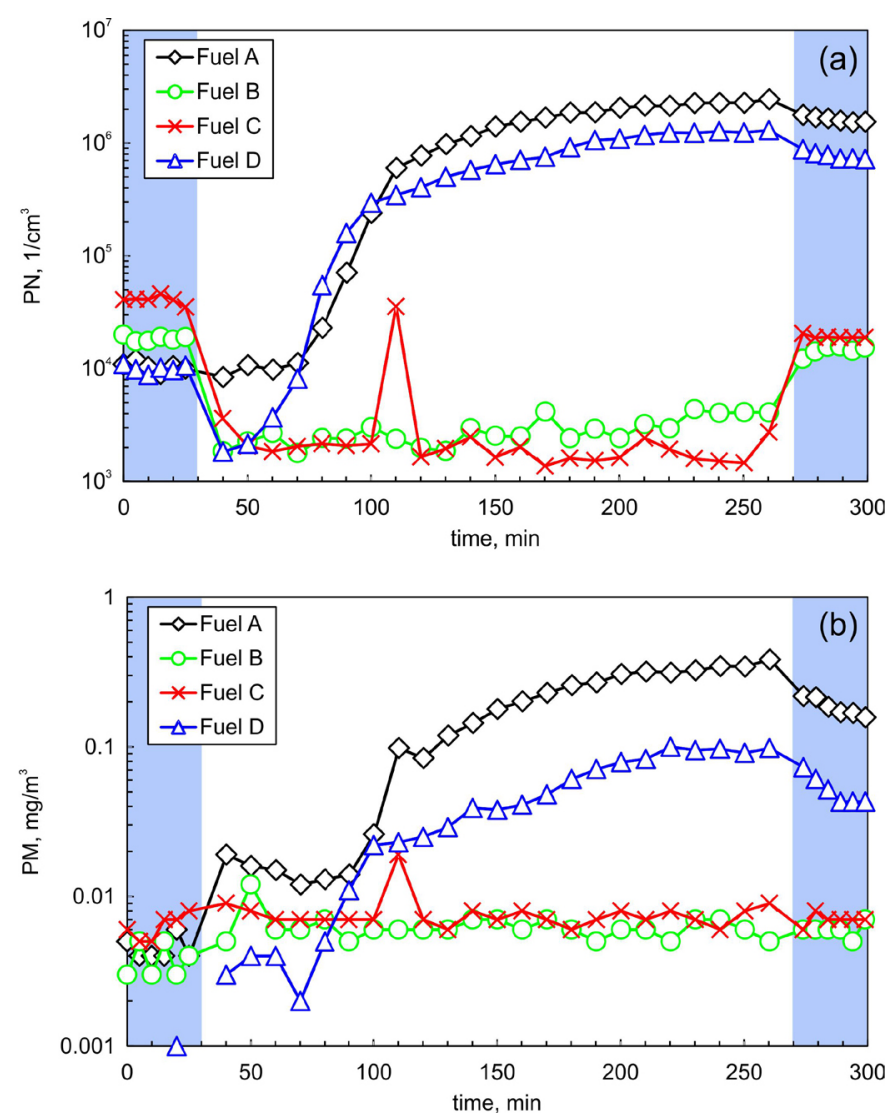

Figure 5. Time signal of (a) PN and (b) PM produced by the engine with the different fuel blends during the injector fouling stage. The light blue regions indicate the operating point at $2000 \mathrm{rpm}$ and 2 bar BMEP.

Overall, the trends seen in the PN drift are also reflected in the PM-time signal. Fuels A and D give a significant growth of PM over a similar time scale. The increase also levels off at the end of the experiment. The largest overall increase is also caused by Fuel A with a maximum above $0.38 \mathrm{mg} / \mathrm{m}^{3}$, which is over an order of magnitude greater than the initial values recorded. In case of Fuels $\mathrm{B}$ and $\mathrm{C}$, no noticeable change over the course of the fouling cycle is recorded. After reducing the engine speed and load at the end of the cycle, a decrease in PM is observed for Fuels A and D. The two blends with detergent (Fuel B and Fuel C) remain constant until shut down of the engine.

Upon completion of the injector fouling cycle, the engine was switched to detergent containing Fuel $\mathrm{C}$ during the clean-up phase using the same experimental procedure outlined for the injector fouling test. Results for PN and PM are presented in Figure 6.Fuels A and D show different response rates in the clean-up cycle. The engine previously run with Fuel A takes the longest to give an emissions reduction. Here the emissions are still about twice the start values observed when an engine runs with new injectors. Fuel D requires the entire 8 hour run to fall back to the initial values observed with clean injectors. Detergent containing Fuels B and C do not show any change in PN in this run, as expected. PM emissions show a similar trend to those observed for PN in that the previous emissions increase is reversed. Within $160 \mathrm{~min}$, the initial PM level is reached for Fuel D, whilst the engine run with Fuel A takes about 400 min to drop back down to start values.
After the engine tests all injectors were visually analysed by microscopy. Figure 7 shows micrographs of one clean injector, one that was fouled with Fuel A and one that was fouled with Fuel A and cleaned-up with Fuel $\mathrm{C}$ afterwards. The entire surface of the injector tip is covered with combustion products in case of the fouled injector. The combustion product build-up forms lumps at the centre of the injector tip and around the nozzles, as can be seen in the detailed view. In addition, the diameter of the injector nozzles appears to be reduced by the deposits. This could affect spray formation negatively and alter the performance of the injector. Additionally, these deposits can act as a sponge, due to their porosity and as such further promote fouling [ㄷ6, $\underline{28}]$.
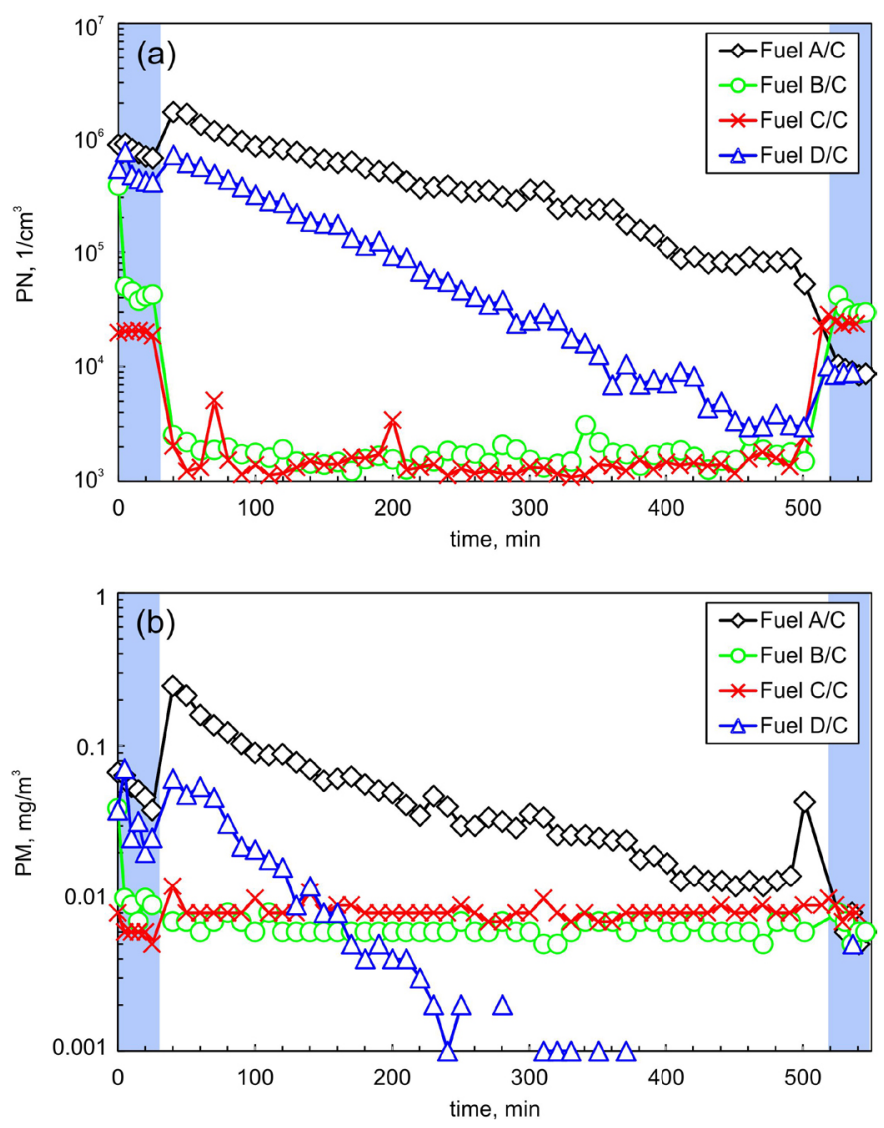

Figure 6. Time signal of (a) PN and (b) PM produced by the engine with the different fuel blends during the injector clean-up phase, using detergent Fuel C only. The light blue regions indicate the operating point at $2000 \mathrm{rpm}$ and 2 bar BMEP.

The injector that was cleaned-up with detergent containing Fuel C illustrates the effectiveness of such an additive. The surface of the injector, especially the bottom half, shows reduced amounts of deposits and the metal surface is more visible. This could be explained by the orientation of the injector in the engine (single hole \#3 is oriented towards the cylinder top) and the tumble motion inside the cylinder created by the air flow, leading to an increased erosion of the deposits on this side. The surface in and around the nozzle wells is almost completely free of combustion products. The remainder of the deposits seem to be smoother and their more glossy appearance could indicate that the porosity is reduced compared to the deposits of the fouled injector. Furthermore, the thickness seems 
to be reduced. Both factors could reduce the soaking-up of fuel during injection and therefore explain why the original injector performance can be restored during clean-up.

These observations are supported, when comparing the micrographs of injectors that were run with the detergent fuels (Fuels B and C) during the injector fouling stage (Figure 8). Both have a similar appearance to those run in the clean-up cycle. The clean appearance of the injector holes correlates well with the low particulate emissions observed during the engine tests. Consequently, the increase in particulate emissions measured can be directly connected to the combustion deposit build-up. To gain further understanding of the impact of injector deposits, the fuel spray patterns of the injectors were analysed.
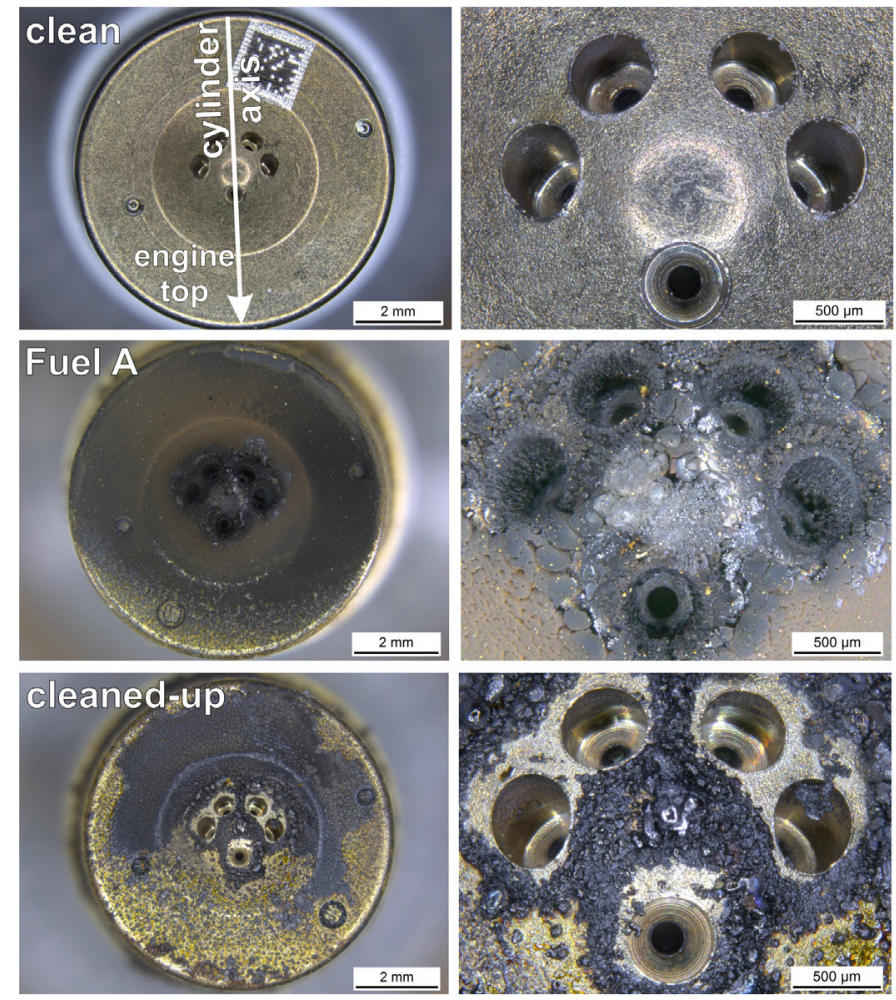

Figure 7. Micrographs of the injectors (left column) and corresponding detailed view of the injector nozzles (right column) of a clean, a fouled and a cleaned-up injector. The fouling was done with Fuel A. The orientation of the injector inside the cylinder is noted in the first micrograph.
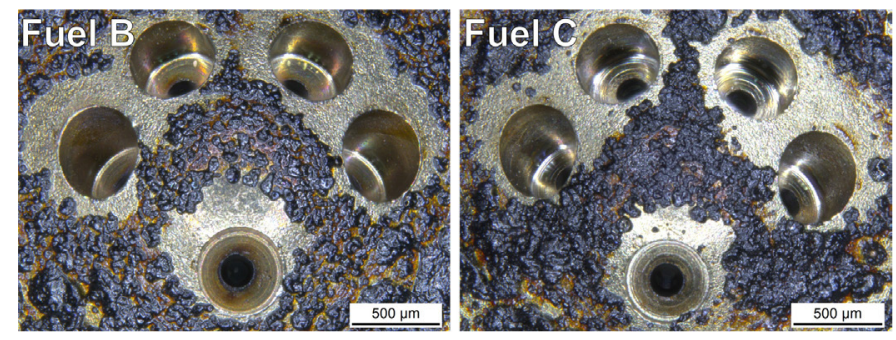

Figure 8. Micrographs of injectors that were used with detergent fuels (Fuel B and $\mathrm{C}$ ) during the injector fouling cycle..

\section{IMAGING RESULTS}

All of the 32 injectors were tested in the laboratory injection chamber. Mean spray patterns were calculated, based on 50 individual recordings, in order to minimize variances caused between injections and to maximise reliability of the data. Figure 9 shows extracted frames of the spray evolution of a clean injector, presented in false colours. The faint vertical line in the centre of the images corresponds to a physical edge of the aluminium injector holder. Intensity values displayed in these images correlate with the local droplet density, causing the incident light to be scattered. This is an established technique to analyse fuel spray patterns and the correlation can be made under the assumption of optically thin sprays, which is reasonable to assume for these types of sprays, with the exception of regions very close to the nozzle and the leading edge during initial spray formation $[\underline{29}, \underline{30}]$. The chosen light source was placed at a large enough distance from the spray, that combined with the wide illumination angle an even illumination of the jets was achieved. Additionally, by placing the light source at a 90 angle relative to the camera axis, the optical overlap between the jets was minimised. The numbers displayed correspond to the values recorded by the camera which are between zero for completely dark and 4096 for completely saturated pixels. These images are used for a qualitative comparison, only.
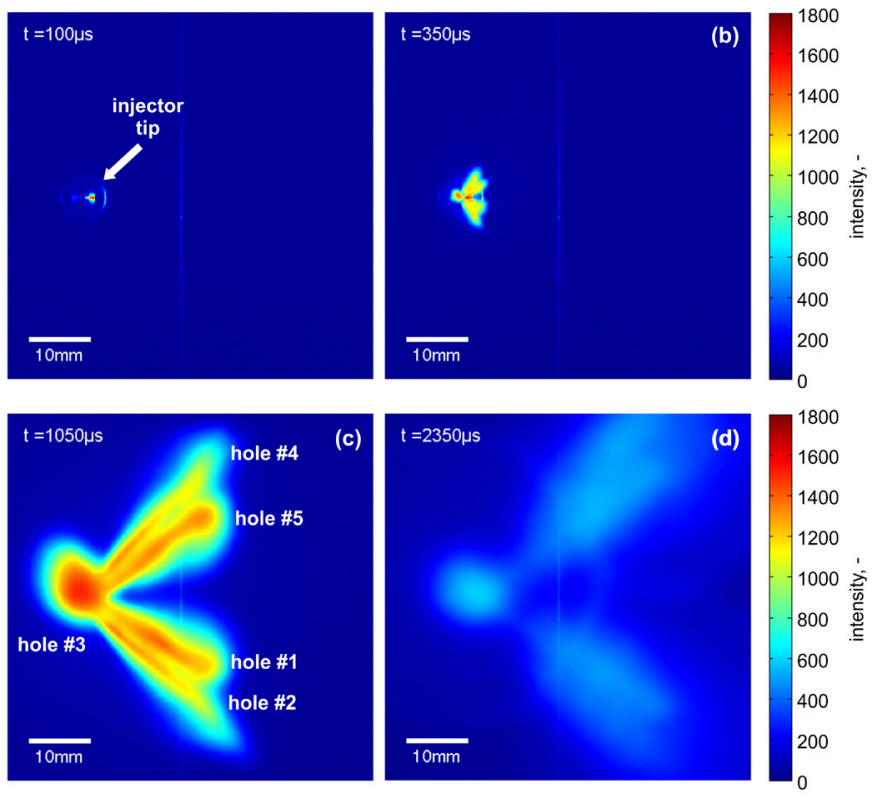

Figure 9. Extracted frames from the mean scattering intensity time series of the clean injector. The timestamp corresponds to the time after triggering the injector.

At the beginning of the recording, no spray is visible (Figure 9a), caused by a delay of the injector needle lift upon triggering the electronics. About $0.35 \mathrm{~ms}$ into the recording the spray appears and all five jets begin to form (Figure 9b). The spray grows and reaches a pseudo steady shape in the recording corresponding to $1.05 \mathrm{~ms}$. This frame is selected to analyse the differences between other injectors. The single jet on the left side (from hole \#3), which is angled almost perpendicular to the plate, shows the largest intensity values. The 
other four jets face outwards and are symmetrically distributed between the top and the bottom half of the image. The two outside jets at both sides appear longer and thinner than their adjacent ones. The front of the two inner jets looks more rounded, and larger intensities are recorded here. Once the injector needle closes, the jets separate from the nozzles and droplet clouds remain suspended in air, travelling outwards (Figure 9d).

Based on this method the fouled and cleaned-up injectors were analysed. Additionally, to further increase the reliability of these investigations it was decided to clean injector sets from both the fouling and clean-up engine cycles in an ultrasonic bath after the initial recordings. After mechanical cleaning, the injector sprays were analysed again in the injection chamber. This allowed comparisons between fouled, cleaned-up and mechanically cleaned injectors. It also isolates the measurements from any potential manufacturing tolerances between injectors. Figure 10 shows spray patterns generated by an injector fouled with Fuel A and one that was run with Fuel A and cleaned-up with Fuel $\mathrm{C}$, next to the respective injectors after mechanical cleaning. The injectors were all taken from the same cylinder.

The outward facing jets produced by the injectors fouled with Fuel A have a noticeably smaller cone angle and their droplet density appears reduced compared to the same injector that was mechanically cleaned. The pattern of the mechanically cleaned injector is more diffuse and the two pairs of jets seem to have merged in these images. Also, the spray intensities are higher compared to the fouled state and the penetration depth is reduced. These observations are verified by the normalised relative difference between the two respective image pairs, as shown in Figure 11. This local quantity was calculated by subtracting the image after mechanical cleaning from the original recording. The results were then normalised by the individual image before the mechanical treatment. Red regions correspond to areas that are only visible in the spray after mechanical cleaning and green regions are only present in the original image before the treatment. Black areas have the same intensity in both images. In comparison, the relative difference of the fouled injector before and after mechanical cleaning (Figure 11a) appears inhomogeneous next to the relative difference of the Fuel C injector (Figure 11b). The large red region in the centre of the image indicates the broader spray cone generated after cleaning the injector. The deeper spray penetration of the fouled injector is highlighted by the green region on the right-hand side of all jets. In comparison, the relative difference calculated from the Fuel $\mathrm{C}$ injector appears notably more even with only a small red area are around the right edge of the bottom jet.

The observations described suggest that the atomisation is impeded for the fouled injector. Larger droplet sizes and reduced evaporation can explain the deeper penetration, as larger droplets are less likely to be decelerated by the surrounding air continuum. Increased penetration depth combined with the reduced atomisation are important factors with regards to particulate emissions, as both can promote wall wetting, which is one of the main contributors to soot in GDI. These observations highlight the impact that injector fouling can have on spray formation, which can ultimately influence fuel combustion and emissions.

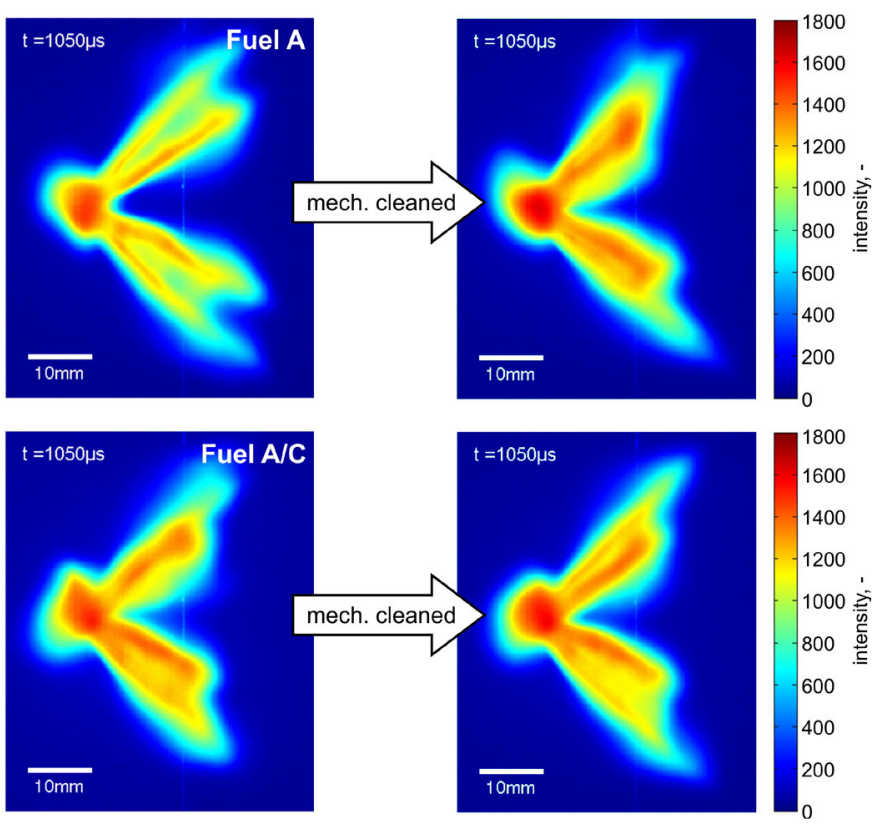

Figure 10. Spray pattern of an injector fouled with Fuel A (top left) in comparison to the spray pattern of a fouled injector that was treated with Fuel C (bottom left) during clean-up. Both injectors are compared to their mechanically cleaned state. These are representative samples from the injectors tested.

The spray patterns generated by the fouled injectors treated with the detergent containing fuel in the clean-up phase are similar to the fouled injectors that were cleaned mechanically. The jets are diffuse and there is no discernible separation of the two pairs of jets in these images. This observation fits with the reduced particulate emissions from the engine test and the reduced deposit formation observed in the micrographs. The spray pattern of an injector from the clean-up cycle that underwent the mechanical cleaning process shows very small before and after changes to the spray pattern. There is only a slight increase in separation between the outer jets, but the shapes are very similar. The changes are much less pronounced compared to those observed when a fouled injector undergoes the same mechanical clean-up process.
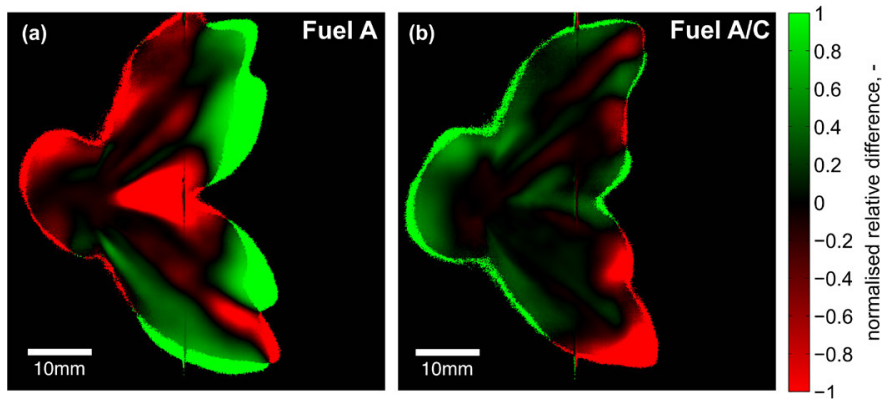

Figure 11. Relative difference between (a) the spray pattern of the injector fouled with Fuel A and the same injector after mechanical cleaning, normalised by the spray pattern of Fuel A and (b) the spray pattern of the fouled injector treated with Fuel $\mathrm{C}$ and the same injector after mechanical cleaning, normalised by the spray pattern of the injector treated with Fuel C.

Overall, we observe a difference in spray pattern between the fouled and cleaned-up injectors. This observation illustrates the effect injector fouling can have on spray formation and how the use of 
Henkel et al / SAE Int. J. Fuels Lubr. / Volume 10, Issue 2 (June 2017)

detergent additives can counter-act these changes. The maintenance of a well atomised spray and reduction of wall wetting can ultimately lead to reduced particulate emissions.

\section{SUMMARY/CONCLUSIONS}

Due to the fuel delivery design of direct injection gasoline engines, injectors are exposed to the harsh environment of the combustion chamber, which can lead to deposit formation on the injector tip. The resultant alteration of the fuel spray can increase engine emissions, particularly PN and PM.

In order to study this effect and the potential of fuel detergency to reduce it, a set of injectors were deliberately fouled in an engine test cycle. The injectors were then cleaned with a detergent containing fuel in a similar engine cycle. During the first cycle an increase of particulate numbers of more than two orders of magnitude was observed. Fuels with detergent additives did not produce any significant increase in particulate emissions during this phase. When the engines operating with fouled injectors were run with detergent containing fuel, particulate emission reverted back to their original levels in most cases. Analysis of the injectors via microscopy confirmed that the fouling on the surface and nozzles of the injector tips correlated with an increase of PN/PM emissions during the engine test. Operating the engine with detergent containing fuel cleaned the injectors and resulted in decreased particulate emissions.

Analysis of the spray patterns in a laboratory injection chamber backed-up the trends observed. Fouled injectors produced sprays with smaller cone angles and deeper penetration depths compared to clean injectors, which can promote wall wetting and lead to particulate emissions through rich fuel combustion.

These results highlight a representative selection of the spray data available, which allows comparison with the PMPN emission from the engine tests. Future work will focus on expanding the results with a systematic and numerical analysis of the spray images.

\section{REFERENCES}

1. Basshuysen, R. van and Spicher, U., "Gasoline Engine with Direct Injection: Processes, Systems, Development, Potential," Springer Verlag, Wiesbaden, ISBN 9783834806703, 2009.

2. Queiroz, C. and Tomanik, E., "Gasoline Direct Injection Engines - A Bibliographical Review," SAE Technical Paper 973113, 1997, doi: $10.4271 / 973113$.

3. Brehob, D., Fleming, J., Haghgooie, M., and Stein, R., "StratifiedCharge Engine Fuel Economy and Emission Characteristics," SAE Technical Paper 982704, 1998, doi:10.4271/982704.

4. Alperstein, M., Schafer, G., and Villforth, F., "Texaco's Stratified Charge Engine - Multifuel Efficient, Clean, and Practical," SAE Technical Paper 740563, 1974, doi:10.4271/740563.

5. Milpied, J., Jeuland, N., Plassat, G., Guichaous, S. et al., "Impact of Fuel Properties on the Performances and Knock Behaviour of a Downsized Turbocharged DI SI Engine - Focus on Octane Numbers and Latent Heat of Vaporization," SAE Int. J. Fuels Lubr. 2(1):118-126, 2009, doi: 10.4271/2009-01-0324.

6. Amann, M. and Ouwenga, D., "Engine Parameter Optimization for Improved Engine and Drive Cycle Efficiency for Boosted, GDI Engines with Different Boosting System Architecture," SAE Technical Paper 2014-01-1204, 2014, doi:10.4271/2014-01-1204.
7. Bandel, W., Fraidl, G., Kapus, P., Sikinger, H. et al., "The Turbocharged GDI Engine: Boosted Synergies for High Fuel Economy Plus Ultra-low Emission," SAE Technical Paper 2006-01-1266, 2006, doi: $10.4271 / 2006-01-1266$.

8. Zhao, F., Lai, M.-C., and Harrington, D.., “Automotive spark-ignited direct-injection gasoline engines," Prog. Energy Combust. Sci. 25(5):437-562, 1999, doi:10.1016/S0360-1285(99)00004-0.

9. Zhao, F., Lai, M., and Harrington, D., "A Review of Mixture Preparation and Combustion Control Strategies for Spark-Ignited DirectInjection Gasoline Engines," SAE Technical Paper 970627, 1997, doi: $10.4271 / 970627$.

10. Anderson, W., Yang, J., Brehob, D., Vallance, J. et al., "Understanding the Thermodynamics of Direct Injection Spark Ignition (DISI) Combustion Systems: An Analytical and Experimental Investigation," SAE Technical Paper 962018, 1996, doi:10.4271/962018.

11. Myung, C.L. and Park, S., "Exhaust nanoparticle emissions from internal combustion engines: A review," Int. J. Automot. Technol. 13(1):9-22, 2012, doi:10.1007/s12239-012-0002-y.

12. Kim, Y., Kim, Y., Jun, S., Lee, K. et al., "Strategies for Particle Emissions Reduction from GDI Engines," SAE Technical Paper 201301-1556, 2013, doi:10.4271/2013-01-1556.

13. Kinoshita, M., Saito, A., Matsushita, S., Shibata, H. et al., "A Method for Suppressing Formation of Deposits on Fuel Injector for Direct Injection Gasoline Engine," SAE Technical Paper 1999-01-3656, 1999,

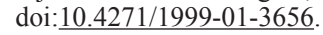

14. Arters, D., Bardasz, E., Schiferl, E., and Fisher, D., "A Comparison of Gasoline Direct Injection Part I - Fuel System Deposits and Vehicle Performance," SAE Technical Paper 1999-01-1498, 1999, doi: 10.4271/1999-01-1498.

15. Xu, H., Wang, C., Ma, X., Sarangi, A.K., Weall, A., and KruegerVenus, J., "Fuel injector deposits in direct-injection spark-ignition engines," Prog. Energy Combust. Sci. 50:63-80, 2015, doi:http://dx.doi. org/10.1016/i.pecs.2015.02.002.

16. Von Bacho, P., Galante-Fox, J., and Sant, D., "Development of a Robust Injector Design for Superior Deposit Resistance," SAE Technical Paper 2005-01-3841, 2005, doi:10.4271/2005-01-3841.

17. Aradi, A., Imoehl, B., Avery, N., Wells, P. et al., "The Effect of Fuel Composition and Engine Operating Parameters on Injector Deposits in a High-Pressure Direct Injection Gasoline (DIG) Research Engine," SAE Technical Paper 1999-01-3690, 1999, doi:10.4271/1999-01-3690.

18. Aradi, A., Colucci, W., Scull, H., and Openshaw, M., "A Study of Fuel Additives for Direct Injection Gasoline (DIG) Injector Deposit Control," SAE Technical Paper 2000-01-2020, 2000, doi:10.4271/2000-01-2020.

19. Aradi, A., Evans, J., Miller, K., and Hotchkiss, A., "Direct Injection Gasoline (DIG) Injector Deposit Control with Additives," SAE Technical Paper 2003-01-2024, 2003, doi:10.4271/2003-01-2024.

20. Ashida, T., Takei, Y., and Hosi, H., "Effects of Fuel Properties on SIDI Fuel Injector Deposit," SAE Technical Paper 2001-01-3694, 2001, doi: $10.4271 / 2001-01-3694$.

21. Noma, K., Noda, T., Ashida, T., Kamioka, R. et al., "A Study of Injector Deposits, Combustion Chamber Deposits (CCD) and Intake Valve Deposits (IVD) in Direct Injection Spark Ignition (DISI) Engines," SAE Technical Paper 2002-01-2659, 2002, doi:10.4271/2002-01-2659.

22. Joedicke, A., Krueger-Venus, J., Bohr, P., Cracknell, R. et al., "Understanding the Effect of DISI Injector Deposits on Vehicle Performance," SAE Technical Paper 2012-01-0391, 2012, doi:10.4271/2012-01-0391.

23. Arters, D. and Macduff, M., "The Effect on Vehicle Performance of Injector Deposits in a Direct Injection Gasoline Engine," SAE Technical Paper 2000-01-2021, 2000, doi:10.4271/2000-01-2021.

24. Prakash, A., Nelson, E., Jones, A., Macias, J. et al., "Particulate Mass Reduction and Clean-up of DISI Injector Deposits via Novel Fuels Additive Technology," SAE Technical Paper 2014-01-2847, 2014, doi: 10.4271/2014-01-2847.

25. Carlisle, H., Frew, R., Mills, J., Aradi, A. et al., "The Effect of Fuel Composition and Additive Content on Injector Deposits and Performance of an Air-Assisted Direct Injection Spark Ignition (DISI) Research Engine," SAE Technical Paper 2001-01-2030, 2001, doi: $10.4271 / 2001-01-2030$.

26. Berndorfer, A., Breuer, S., Piock, W., and Von Bacho, P., "Diffusion Combustion Phenomena in GDi Engines caused by Injection Process," SAE Technical Paper 2013-01-0261, 2013, doi:10.4271/2013-01-0261. 
27. Wang, C., Xu, H., Herreros, J.M., Wang, J., and Cracknell, R., "Impact of fuel and injection system on particle emissions from a GDI engine," Appl. Energy 132:178-191, 2014, doi:http://dx.doi.org/10.1016/j. apenergy.2014.06.012.

28. Harrison, A., Cracknell, R., Krueger-Venus, J., and Sarkisov, L., "Computer Simulation Studies of Adsorption of Binary and Ternary Mixtures of Gasoline Components in Engine Deposits," SAE Int. J. Fuels Lubr. 7(3):756-761, 2014, doi:10.4271/2014-01-2719.

29. Parrish, S. and Farrell, P., "Transient Spray Characteristics of a DirectInjection Spark-Ignited Fuel Injector," SAE Technical Paper 970629, 1997, doi:10.4271/970629.

30. Zhao, F., Harrington, D., and Lai, M.C., "Automotive Gasoline DirectInjection Engines," (Warrendale, Society of Automotive Engineers, Inc., 2002), ISBN:9780768008821.

\section{CONTACT INFORMATION}

Dr. Sebastian Henkel

Department of Mechanical Engineering Imperial College London, Exhibition Road London SW7 2BX, United Kingdom sebastian.henkel@imperial.ac.uk

\section{DEFINITIONS/ABBREVIATIONS}

BMEP - brake mean effective pressure

CA - crank angle

CO - carbon monoxide

GDI - gasoline direct injection

LEV - low emissions vehicle

NO - nitric oxide/nitrogen dioxide

PFI - port fuel injection

PM - particle mass

$\mathbf{P N}$ - particle number

SOI - start of ignition

T90 - fuel distillation temperature at $90 \%$ recovery

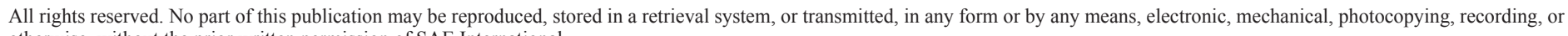
otherwise, without the prior written permission of SAE International. 